\title{
Mobile Application Development of Managing Elderly Household Accounts Using Speech Recognition
}

\author{
https://doi.org/10.3991/ijim.v14i02.11651 \\ Sumitra Nuanmeesri \\ Suan Sunandha Rajabhat University, Bangkok, Thailand \\ sumitra.nulssru.ac.th
}

\begin{abstract}
Using spoken language is the easiest and most natural way of communication for human beings. The communication between humans and machines using sounds or language is a huge move forward. This article demonstrates the development of a mobile application for managing household accounts with the integration of a speaking voice and touch-screen function on smartphones; this could also be used as a tool to manage household accounts for elderly Thai people. The content was evaluated by five experts to identify each feature of the developed mobile application. Afterwards, the developed mobile application was distributed to thirty-three elderly people. The findings showed that the elderly people were able to learn and use the mobile application effectively. The learning post-test results scored higher than the pre-test results. The effectiveness evaluation results in terms of the accessibility barriers that can be faced by elderly people while using mobile applications showed that the average mean was 4.13 and the standard deviation was 0.34 and the acceptance of the mobile application based on accessibility barriers that could be detected by elderly people while being used has high consensus. This indicates that the developed mobile application is effective for elderly users at a high level.
\end{abstract}

Keywords-Mobile application, elderly system, household account, speech recognition.

\section{Introduction}

Thailand has entered an aging society in which the elderly population (aged 60 years old or more) increased from $6.8 \%$ of the total population in 1994 to $14.9 \%$ in 2014 ; $45.1 \%$ were made up of elderly men and $54.9 \%$ were taken up by elderly women. The elderly population had risen from $6.8 \%$ of the total population in 1994 to $9.4 \%$ and $10.7 \%$ in 2002 and 2007, respectively. By 2011, they had grown to $12.2 \%$. In other words, Thailand is one of the ASEAN member countries who are entering into an aging society. An aging society refers to the rise of the elderly population (when citizens aged 60 years old or over comprise $10 \%$ or more of the total population), while the youth and working populations reduce [1]. The fact that the elderly population accounts for more than $10 \%$ of the total population indicates a genuine aging society [2]. Scholars estimate that Thailand will have 14.4 million elderly people by 2025 and reach $27 \%$ of 
the total population in 2050, in which women will have a longer life expectancy by 45 years than men on average [1].

Statistically, the household debts in 2018 amounted 12.8 trillion baht; they had increased by $6 \%$ and accounted for $78.6 \%$ of the country's GDP for two respective quarters. When compared to other countries, Thailand was ranked 10th among 89 states and 3rd among 29 in terms of household debts to GDP. In 2019, Thai household debts rose to 10th in Asia [3]. The household accounting, hence, must be managed since the financial discipline works as an immunity for all ages and both genders. Having sufficient knowledge and tools as well as real practice in order to notice the unnecessary expenditures can help them reduce such expenses and save more money for their old age when they would have lower incomes. This is because, if debts are made by older people, it will be burdensome and negatively affect both their children and themselves.

Now digital technology, software and smartphones have been rapidly developed and are playing a huge role in the modern way of living. According to elderly people are likely to use the internet to some degrees [4]. The older people are not only able to use mobile applications for surfing, engaging in social networks and staying in touch with their families and friends, but they also use the interface for practical purposes like traveling, finance, education and shopping. This research applies the digital technology as well as computer software to the development of a mobile application for managing elderly Thai people's household accounts on mobile devices. This application will allow them to use their smartphones to manage their household accounts by giving commands to the interface on their smartphones. The older people can use spoken commands and touch screens to operate their household accounting. This can alleviate the limitations of their eyesight due to their aging and reduce the problems of unclear tinysized displays on the relatively small smartphones, while considering the mentality of the older people who still believe that they have the same capability as the younger people and acknowledging their privacy. Giving commands by using speaking voices solely also allows others to hear the commands. Since elderly people in Thailand mostly live with their children and grandchildren as an extended family, they play a significant role in taking care of the household accounts. Elderly people therefore can be the role model for the younger generations in terms of household accounting, and helping them become more financially disciplined and reduce the household debts of Thailand as a whole. More importantly, household accounting can help them train their brains, give them daily activities and diminish their exposure to the major depression disorders and dementia. This paper is consisted of different sections as follows. The Section 2 includes the studies on the speech recognition and previous researches. The principles and concepts of speech recognition will be applied to the development of the mobile application of managing household accounts with the integration of a speaking voice and touch-screen function on smartphones is presented in Section 3. In Section 4, there are the results of the effectiveness evaluation of the mobile application. Finally, a conclusion is provided in Section 5. 


\section{Speech Recognition}

Speech recognition (SR) is the interpretation of spoken words into texts [4]. Precisely, it can be defined as recognizing voice by computer and operating the requisite task. The process of speech recognition converts a speech signal to an order of words as a computer program [5]. It is additionally known as 'automatic speech recognition' (ASR), 'computer speech recognition' (CSR) or 'speech to text' (STT). Speech recognition technology has granted computers the ability to follow human voice commands and comprehend human languages.

\subsection{Probability theory of speech recognition}

The fundamental purpose of a speech recognition system is to figure out the most distinct symbol order out of all the valid sequences in the language $\mathrm{L}$, from the given acoustic input $\mathrm{O}$ [6]. As mentioned above, the input refers to a set of distinct observations, in the way that

$$
o=o_{1}, o_{2}, o_{3}, \ldots, o_{t}
$$

Likewise, the symbol sequence to be noticed is represented as:

$$
\mathrm{W}=\mathrm{w}_{1}, \mathrm{w}_{2}, \mathrm{w}_{3}, \ldots, \mathrm{w}_{\mathrm{n}}
$$

The primary ASR system goal can then be explained as:

$$
\widehat{\mathrm{W}}=\operatorname{argmax} \mathrm{P}(\mathrm{W} \mid \mathrm{O}) \text { for } \mathrm{W} \epsilon \mathrm{L}
$$

This equation implies that, for a given sequence $\mathrm{W}$ and acoustic input sequence $\mathrm{O}$, the probability $\mathrm{P}(\mathrm{W} \mid \mathrm{O})$ needs to be defined. It is possible to apply Bayes' theorem to this probability to obtain the following equation:

$$
\mathrm{P}(\mathrm{W} \mid \mathrm{O})=\frac{\mathrm{P}(\mathrm{O} \mid \mathrm{W}) \mathrm{P}(\mathrm{W})}{\mathrm{P}(\mathrm{O})}
$$

The quantities on the right-hand side of the equation are less complicated to calculate than $\mathrm{P}(\mathrm{W} \mid \mathrm{O})$. $\mathrm{P}(\mathrm{W})$ which represents the preceding probability for the sequence itself. The calculation is made by applying the prior knowledge of occurrences of the sequence $\mathrm{W}$. As each candidate sentence $\mathrm{W}$ has the same $\mathrm{P}(\mathrm{O})$, the equation 4 can be interpreted as [7].

$$
\widehat{\mathrm{W}}=\operatorname{argmax} \frac{\mathrm{P}(\mathrm{O} \mid \mathrm{W}) \mathrm{P}(\mathrm{W})}{\mathrm{P}(\mathrm{O})}=\operatorname{argmax} \mathrm{P}(\mathrm{O} \mid \mathrm{W}) \mathrm{P}(\mathrm{W}) \text { for } \mathrm{W} \in \mathrm{L}
$$

The probability $\mathrm{P}(\mathrm{O} \mid \mathrm{W})$ or the tendency of the acoustic input $\mathrm{O}$, given the sequence $\mathrm{W}$, refers to the observation likelihood called the 'acoustic score'. By employing the Hidden Markov Model, this quantity can be identified [7]. 


\subsection{Speech recognition architecture}

A general speech recognition system is established with key elements consisting of acoustic front-end, acoustic model, lexicon, language model and decoder as illustrated in Figure 1. Acoustic front-end is responsible for transforming the speech signal into consistent features which contributes appropriate data for recognition. The input audio waveform from a microphone is transformed into an array of fixed-size acoustic vectors; this process is called 'feature extraction'. The calculation of parameters of word/phone models is operated by using the acoustic vectors of training data. The decoder functions in a way so that it will search through all possible word sequences in order to discover the sequence of words that will possibly achieve the most. The probability is indicated when an acoustic model $\mathrm{P}(\mathrm{O} \mid \mathrm{W})$ and $\mathrm{P}(\mathrm{W})$ are identified by a language model [8].

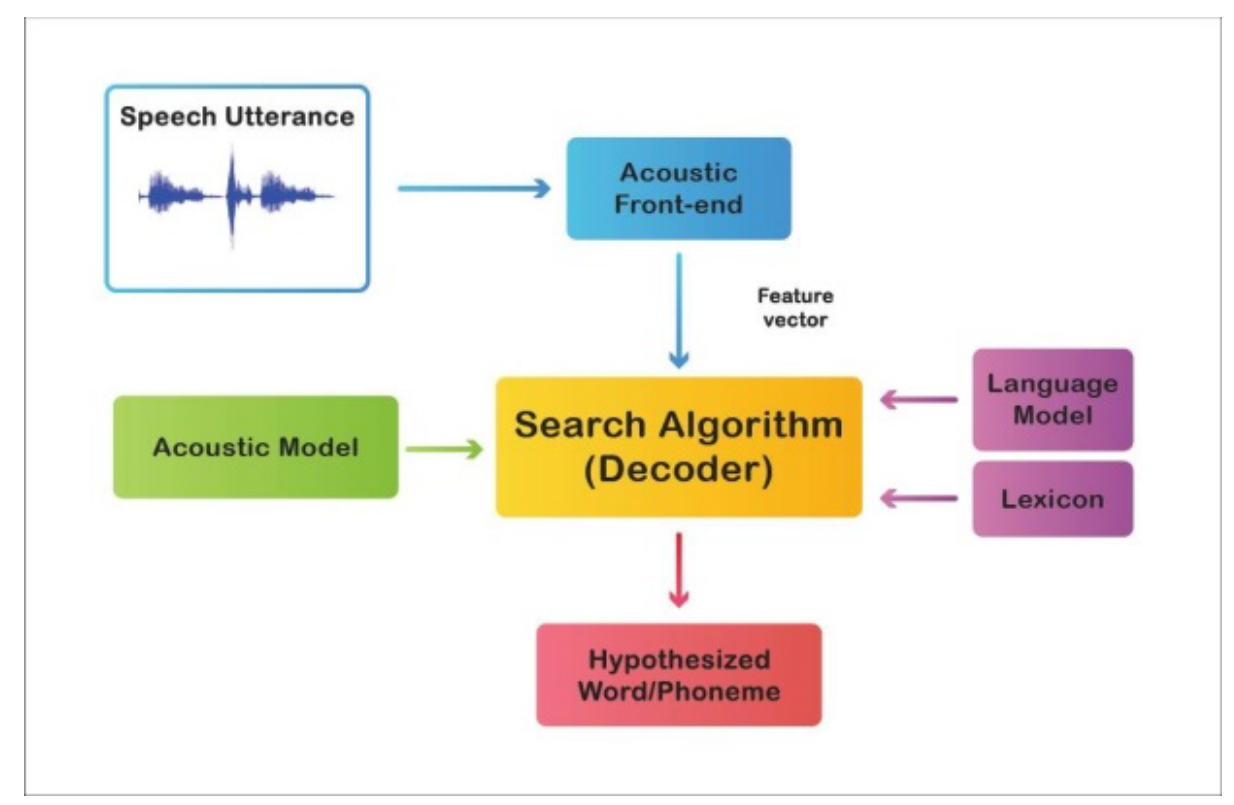

Fig. 1. Speech Recognition System Structure

The performance of an automatic speech recognition system can be illustrated as an extraction of a sum of speech parameters obtained from the acoustic speech signal for each word or sub-word unit. The speech parameters depict the word or sub-word by their changes over time, collectively building up a pattern that portrays the word or subword. In a training stage, all the words of the vocabulary will be read by the operant during the ongoing operation. Afterwards, the word patterns are stored and then, when a word is to be identified, its pattern will be matched with the stored patterns and the word that provides the best match is chosen [8]. This technique is normally called 'pattern recognition'. 


\subsection{Automatic speech recognition techniques}

The establishment of automatic speech recognition techniques are applied to support elderly households. Speech recognition is expected to give the best results in the case of elderly people. Devoted speech corpora were transcribed and used for developing generic speech recognizers to this group of the population. The assessment results of the first experiments were adopted to draw conclusions about the alarm called 'detection'. The second experiments included participants who had tried the fall scenarios in a practical smart home; $67 \%$ of the distress calls were found online [9]. The PaeLife project is a European business-scholar collaboration in the scheme of the Ambient Assisted Living Joint Program (AALJP), which aims to develop a multi-mode, polyglot digital personal life assistant to support elderly citizens who are socially incorporated. Using oral expressions is a dominant interaction mode of AALFred, which is the Windows application invented in the project. The application can be conducted employing speech input in four different European languages, including French, Hungarian, Polish and Portuguese. This research concisely introduces the personal life assistant and later emphasizes the speech-involved accomplishments of the project such as the collection, transcription and annotation of huge corpora of elderly speech, the invention of automatic speech recognizers revised for elderly speakers, a speech modality factor that can conveniently be used again in other applications, and an automatic grammar translation service which permits a rapid increase in the application of automatic speech recognition in new languages [10]. The study of the development of the Automatic Speech Recognition Techniques is applied to the mobile application development for seniors in order to support the elderly way of living in different aspects of life. This article will present the development of the mobile application for elderly household account management towards the commands made by speeches and touchscreens. The researchers also considered the mentality of older people who still believe that they share the same capability as the younger generations as well as their need for privacy. This will allow the serious to enjoy the mobile application by designing and developing it for elderly household accounting as mentioned in Section 3.

\section{Methodology}

The research methods for studying the development of a mobile application for managing household accounts using Thai speech recognition include the following steps:

\subsection{Collection data}

This research had conducted the data collection for household accounting consisting of when the dates, incomes and expenses were made, lists of recorded items earned and/or spent, the amount of money earned on each day, the amount of money spent on each day, remarks working as self-reminders, the total amounts of money earned and spent each month, data and the amount of money indicating the differences between incomes and expenses and, finally, the recorded amount of savings in case the number 
of incomes are higher than the number of expenses. Normally, older people tend to record their household accounts on paper.

\subsection{The design of the mobile application}

The information was collected from the data collection process to develop the features in the mobile application. The consistency of the contents was analyzed by five experts in the field of information technology and accounting. Accordingly, the information was taken from the experts to determine the IOC value by using the formula as presented in the equation [11]:

$$
\mathrm{IOC}=\frac{\sum \mathrm{R}}{\mathrm{N}}
$$

$\sum \mathrm{R}$ is the sum of the scores that the experts rate.

$\mathrm{R}$ is the score that the experts rated.

$\mathrm{N}$ is the number of the experts.

The features in the mobile application were assessed by five experts specializing in the field of information technology and accounting. The Index of item objective congruence (IOC) was applied to the evaluation [12][13][14] to determine scores. If the criteria measured by the IOC value of each indicator was higher than 0.5 (the highest IOC value is 1), it could be implied that the features met the objectives and possessed the contents suitable for the operation, showing that the features worked effectively. For instance, if the IOC value of each indicator was 0.8 , it means the features met the objective and were suitable for using in the evaluation. The experts were able to give a rating by considering the assessment criteria as shown in Table 1 .

Table 1. The criteria of content consistency for identifying features in the mobile application development

\begin{tabular}{|c|l|}
\hline Rating criteria & \multicolumn{1}{|c|}{ Meaning } \\
\hline 1 & $\begin{array}{l}\text { There is content consistency, showing the suitability to be used as a feature in the appli- } \\
\text { cation. }\end{array}$ \\
\hline 0 & $\begin{array}{l}\text { There is uncertainty in the content consistency, resulting in its inappropriateness to be } \\
\text { used as a feature in the application }\end{array}$ \\
\hline-1 & $\begin{array}{l}\text { There is neither content consistency nor appropriateness to be used as a feature in the ap- } \\
\text { plication. }\end{array}$ \\
\hline
\end{tabular}

Figure 2 summarizes the IOC evaluation to identify features for the operation of the elderly household accounting mobile application. 


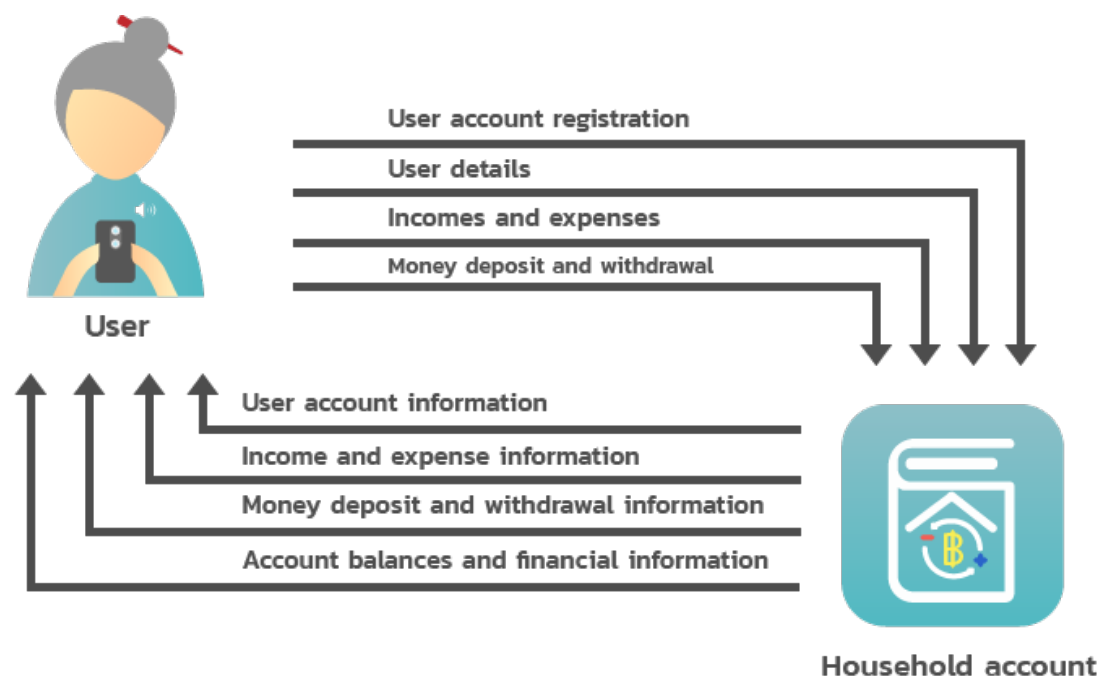

Fig. 2. The feature in the operation of the mobile application

\subsection{Development of the mobile application}

According to the design stage, this research aims to develop the application that works with both iOS and Android operational systems by applying the Ionic Framework, which consists of HTML, TypeScript and Ionic Speech Recognition. The process involves the information hyperlinks on WebServer which is the host service for clients. JSON is applied to share the data, while the data are stored in a MySQL database showing the architecture used in the development of the mobile application as shown in Figure 3 .

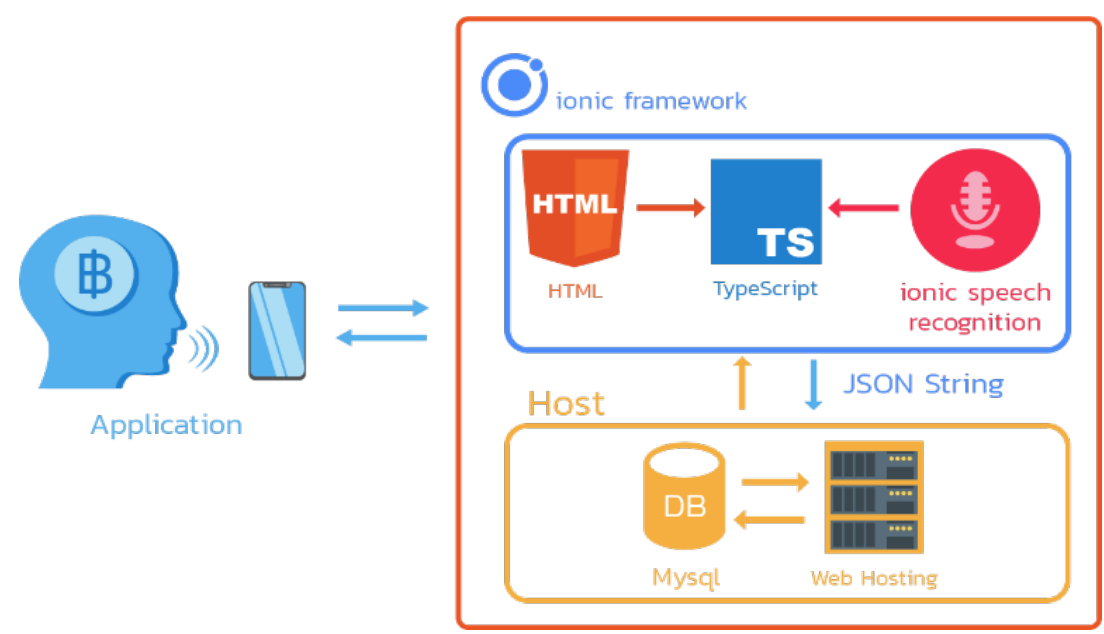

Fig. 3. The architecture used in the development of the mobile application 
Before developing the mobile application. There has been a process for testing the validity of ionic speech recognition in Thai speech recognition related to recording household account information and menus in the application. By five experts in the field of information technology, Thai language, and accounting. The accurate results are $98 \%$ in Thai speech recognition related to household account information and menus in the system. The results from all experts are consistent in the same direction.

The development of the inputs and outputs was designed by using colors to differentiate the incomes, expenses and savings in order to allow the elderly people to use the menu function in the mobile application conveniently; they can memorize the information by colors. There are two methods to give commands in the developed mobile application: speech and touchscreens as shown in Figure 4.

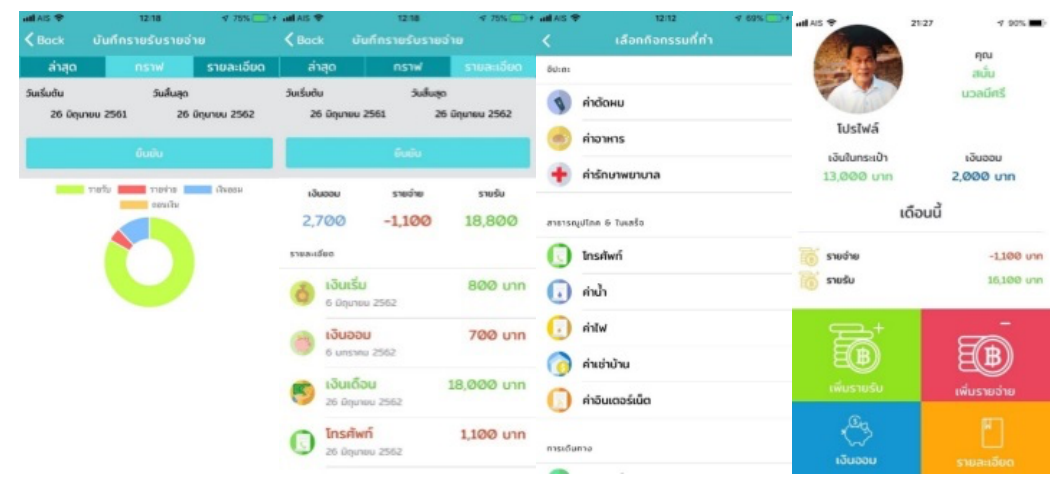

Fig. 4. The example of the mobile application display

The mobile application was validated with black box all 3 aspects: functional test, usability test and performance test [15] by 5 experts in the field of information technology and accounting. The data were analyzed to gain the mean value and the standard deviation value in regards to the Likert-scale scoring criteria [16] as illustrated in Table 2. The mean value at 4.67 together with the standard deviation value at 0.49 . This suggests that the accuracy of mobile application at the highest level.

\subsection{The mobile application training for elderly people}

The training was provided to thirty-three elderly people who were the voluntary subjects participating in the mobile application test advertised on social networks. In this study, the participants received the documents explaining the protocols and research ethical conducts to sign. The 2-hours training involved a lecture, a demonstration and real practice to try out the mobile application. There was a guest speaker who was a lecturer in the field of information technology and fifteen information technology students as assistants. Both the guest speaker and the assistants had tested the developed mobile application and had participated before in the academic service projects related to mobile applications and social media for the elderly community. 
The guest speaker used PowerPoint slides when giving the lecture and demonstrated the installation and the utilization of the mobile application practically with the use of a projector. Each participant received a copy of the lecture materials which illustrated the procedures and the explanations of how to use the mobile application. The participants literally practiced with the mobile application while the guest speaker was their supervisor and advisor. After the training, there were 1-hour online pre- and post-learning tests created by Google Form. The guest speaker explained and gave advice to the participants before taking the tests by using the projector. The assistants took care of and guided the participants on how to access the pre-test and post-test. However, the guest speaker and the assistants did not persuade or complete the tests for the elderly people. The tests consisted of ten questions each, in which the order of questions and answers in the pre-test and post-test were switched around. Finally, once the post-test was completed by all of the participants, the guest speaker gave the answers and stated where the training materials were published and could be downloaded. This included the mobile application demonstration video which was published on social media for the seniors to watch and give the others information about the application.

\subsection{The evaluation of the mobile application's effectiveness}

The effectiveness of the mobile application was evaluated by thirty-three sample who were elderly people. Once the training ended, the people then evaluated the effectiveness of the application in a survey on Google Form by focusing on the accessibility barriers that older people might confront while using the mobile application [17]. This is a key factor that must be considered when developing a mobile application for older people. There were nineteen evaluation criteria which included the font size [18][19], text and complex languages [20][21], lack of help options [20], small space to click [22][23], vertical and horizontal screen orientation [21][24][25], little spacing between contents [25][26], automatic screen lock [27], difficulty with the touch screen [21][23][25][28], virtual or physical keyboard with small size [28][29], error messages without clarity [18][21][28], contrast [18][23][26][30], the difficulty of accessing the menu and submenus [19][24][26][28][31], inaccessible data insertion interfaces [24][28][30], difficulty with drag-and-drop features [23][28][32], difficulty in recognizing the symbols and icons shown in the application [19][28][33], recognition complications of audio notifications and reminders [23], complicated navigation and information flow, lack of options to resize the text [30] and poor sound quality [28]. The data were analyzed to gain the mean value and the standard deviation value in regards to the Likert-scale scoring criteria [16] as illustrated in Table 2.

Table 2. Scoring criteria for evaluating the mobile application

\begin{tabular}{|c|c|l|}
\hline Scale & Range of Weighted Mean & Level of effective mobile application \\
\hline 5 & $4.51-5.00$ & The highest \\
\hline 4 & $3.51-4.50$ & The high \\
\hline 3 & $2.51-3.50$ & The medium \\
\hline 2 & $1.51-2.50$ & The little \\
\hline 1 & $1.00-1.50$ & The least \\
\hline
\end{tabular}




\section{$4 \quad$ Results}

The evaluation results of the developed mobile application are described as follows.

\subsection{The evaluation with respect to the learning outcomes}

The effectiveness evaluation results obtained from the learning outcomes of the trained sample people were collected from the pre-test and post-test before and after the training. There were ten questions in each test by which the order of questions and the answers were shifted around to create some differences between the tests. The results demonstrated that the samples had better learning results when compared to the prior outcomes, as presented in Figure 5.

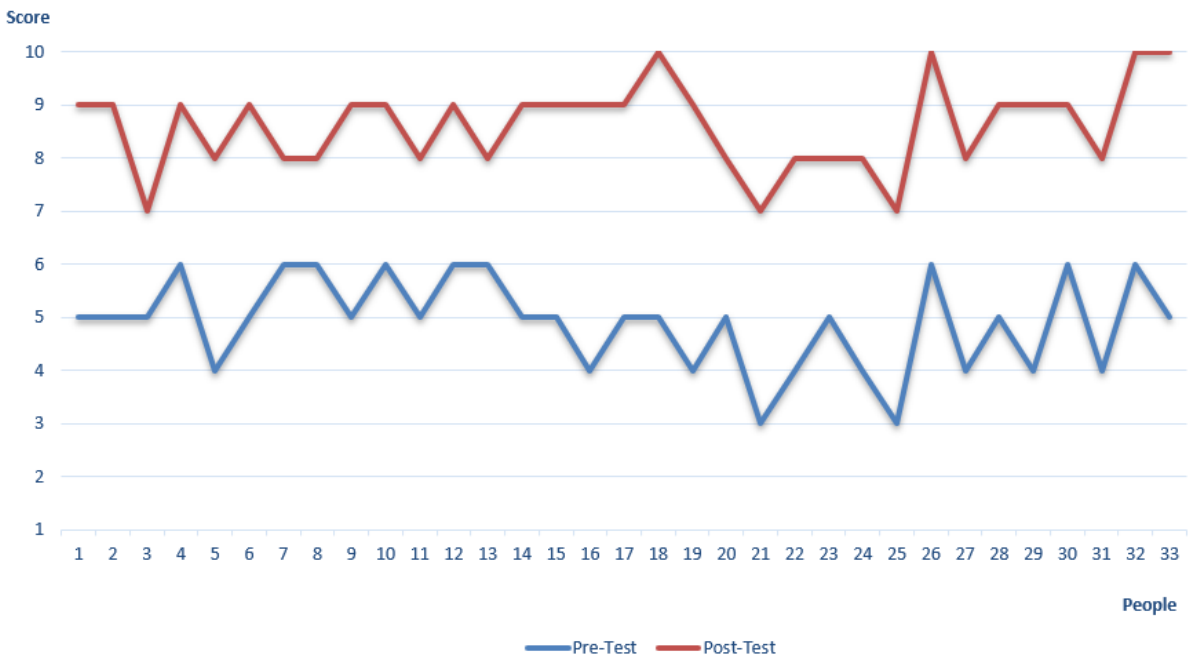

Fig. 5. The learning results based on the mobile application utilization by elderly people

The pre-test and post-test results after the mobile application training from thirtythree people revealed that the post-test results of the sample group after training was better than their pre-test results. The results were analyzed by comparing the number of the subjects who could answer the questions correctly with their individual results. The learning results showed that the subjects had more correct answers after the training. From the comparative test results collected before and after the training, according to the statistical test of the following hypothesis:

The hypothesis was assumed as followed:

H0: The learning result before and after using the mobile application were not different.

H1: The learning result before and after using the mobile application was different. 
Statistically tested by T-Test, the main hypothesis $(\mathrm{H} 0)$ was rejected because the significance value was lower than the significance level $(\alpha)$ which was previously determined. In this study in which $\alpha=0.05$, the $\mathrm{H} 0$ was rejected and the $\mathrm{H} 1$ was accepted.

The efficiency of the developed model was different in their methods. From the Table of Pair Sample Testing, the significance value was analyzed to consider whether the mean values of the two groups were different. In fact, it was found that the significance value was lower than the predetermined significance level. Therefore, the mean values of the two groups were different. Considering the comparative differences of the learning results both before and after the use of the mobile application, it was found that there were differences at the statistical significance $p$ value $<0.001$ show as Table 3 .

Table 3. Comparation test results before and after the training, according to the statistical test of the hypothesis

\begin{tabular}{|c|c|c|c|c|c|c|c|}
\hline \multirow{2}{*}{$\begin{array}{c}\text { Comparison is- } \\
\text { sue }\end{array}$} & \multirow{2}{*}{$\mathbf{N}$} & \multicolumn{2}{|c|}{ Pre-test } & \multicolumn{2}{|c|}{ Post-Test } & \multirow{2}{*}{$\mathbf{t}$} & \multirow{2}{*}{$\mathbf{P}$} \\
\hline & & Mean & $S D$ & Mean & $S D$ & & \\
\hline Learning results & 33 & 4.91 & 0.88 & 8.61 & 0.83 & -24.042 & .000 \\
\hline
\end{tabular}

\subsection{The effectiveness evaluation of the mobile application from the comprehen sion and user experience aspects}

The evaluation indicators of the developed mobile application were assessed by thirty-three sample elderly people. The data were analyzed to determine the mean value the standard deviation value and percentage based on the Likert-scale scoring criteria [16].

The effectiveness evaluation results of the mobile application, focusing on the accessibility barriers that could be detected by elderly people while using the mobile application, showed that, among the nineteen indicators, "Easy to identify the symbols and icons used in the application" criteria had the highest mean value at 4.67 together with the standard deviation value at 0.48 , followed by "Easy of access to the menu and submenus" with the mean value of 4.52 and the standard deviation of 0.51 . Next, "Spacing between contents" received the mean value of 4.30 and the standard deviation value of 0.47 . The other indicators had almost the same mean value which was higher than 4.01, meaning the effectiveness level was high. The overall mean was 4.13 and the overall standard deviation was 0.34 , showing that the developed mobile application was highly effective when the users were elderly people, as shown in Table 4 and Figure 6 presents the comparison between the arithmetic means. 
Table 4. The evaluation results of the mobile application based on accessibility barriers that could be detected by elderly people while being used

\begin{tabular}{|c|c|c|c|}
\hline Assessment Indicators & Mean & SD & $\begin{array}{c}\text { Level of effective mobile } \\
\text { application } \\
\end{array}$ \\
\hline 1. Font Size & 4.03 & 0.17 & The high $(80.61 \%)$ \\
\hline 2. Text and complex languages & 4.12 & 0.33 & The high $(82.42 \%)$ \\
\hline 3. Help options & 4.12 & 0.32 & The high $(82.42 \%)$ \\
\hline 4. Space to click & 4.06 & 0.24 & The high $(81.21 \%)$ \\
\hline 5. Vertical and horizontal screen orientation & 4.03 & 0.17 & The high $(80.61 \%)$ \\
\hline 6. Spacing between contents & 4.30 & 0.47 & The high $(86.06 \%)$ \\
\hline 7. Automatic screen lock & 4.03 & 0.17 & The high $(80.61 \%)$ \\
\hline 8. Easy to use touch screen & 4.03 & 0.17 & The high $(80.61 \%)$ \\
\hline 9. Virtual or physical keyboard & 4.12 & 0.42 & The high $(82.42 \%)$ \\
\hline 10. Error messages & 4.12 & 0.42 & The high $(82.42 \%)$ \\
\hline 11. Contrast & 4.06 & 0.24 & The high $(81.21 \%)$ \\
\hline $\begin{array}{l}\text { 12. Ease of access to the menu and sub- } \\
\text { menus }\end{array}$ & 4.52 & 0.51 & The highest $(90.30 \%)$ \\
\hline 13. Accessible data insertion interfaces & 4.03 & 0.30 & The high $(80.61 \%)$ \\
\hline 14. Easy with drag-and-drop features & 4.06 & 0.24 & The high $(81.21 \%)$ \\
\hline $\begin{array}{l}\text { 15. Easy to identify the symbols and icons } \\
\text { used in the application }\end{array}$ & 4.67 & 0.48 & The highest $(93.33 \%)$ \\
\hline $\begin{array}{l}\text { 16. Perception of audio notifications and re- } \\
\text { minders }\end{array}$ & 4.06 & 0.24 & The high $(81.21 \%)$ \\
\hline 17. Easy navigation and information flow & 4.12 & 0.33 & The high $(82.42 \%)$ \\
\hline 18. An option to resize the text & 4.03 & 0.30 & The high $(80.61 \%)$ \\
\hline 19. Sound quality & 4.03 & 0.30 & The high $(80.61 \%)$ \\
\hline Total & 4.13 & 0.34 & The high $(82.68 \%)$ \\
\hline
\end{tabular}

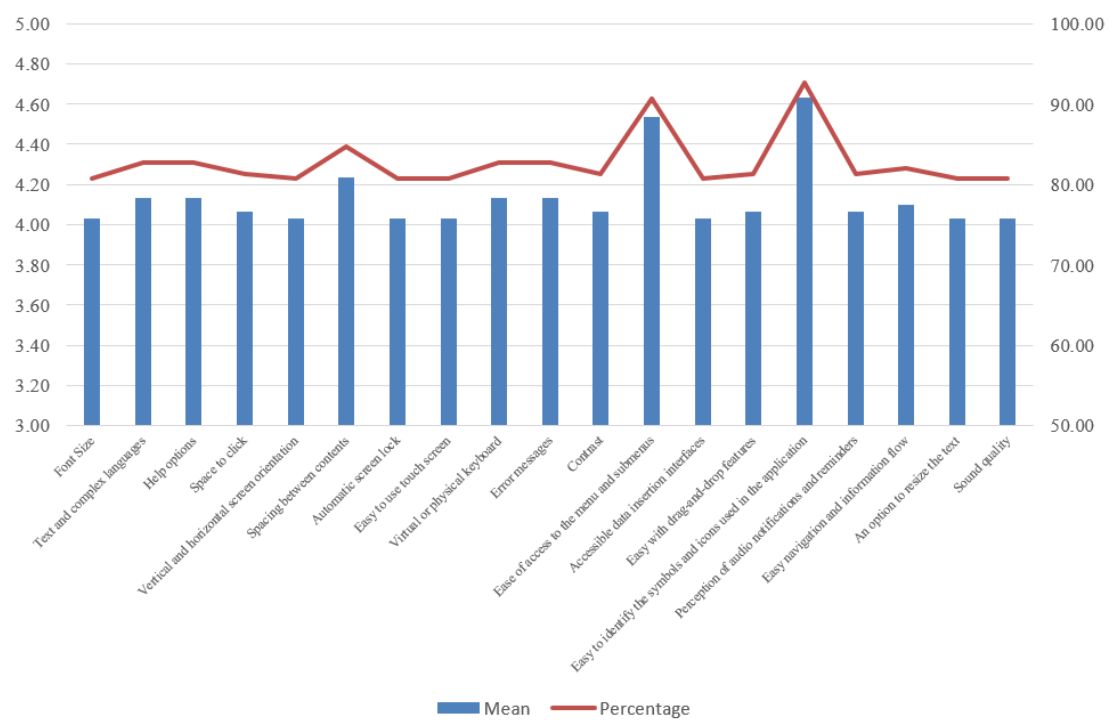

Fig. 6. The comparison between the arithmetic means value of the mobile application based on accessibility barriers 
The result of evaluation for acceptance of the mobile application based on accessibility barriers that could be detected by elderly people while being used has high consensus. All of values the interquartile range no more than 1 [34] and the quartile deviation no more than 0.5 [35] in 19 assessment indicators shows as Table 5.

Table 5. The result of evaluation for acceptance of the mobile application based on accessibility barriers that could be detected by elderly people while being used comparation test results before and after the training, according to the statistical test of the hypothesis

\begin{tabular}{|l|c|c|c|c|c|c|c|}
\hline \multicolumn{1}{|c|}{ Assessment Indicators } & Mean & \multirow{2}{*}{ SD } & \multicolumn{3}{c|}{ Quartiles } & Interquar- & $\begin{array}{c}\text { Quartile } \\
\text { tile Rang }\end{array}$ \\
\cline { 5 - 8 } & & & Q1 & Median & Q3 & \\
\hline 1. Font Size & 4.03 & 0.17 & 4 & 4 & 4 & 0 & 0 \\
\hline 2. Text and complex languages & 4.12 & 0.33 & 4 & 4 & 4 & 0 & 0 \\
\hline 3. Help options & 4.12 & 0.32 & 4 & 4 & 4 & 0 & 0 \\
\hline 4. Space to click & 4.06 & 0.24 & 4 & 4 & 4 & & \\
\hline $\begin{array}{l}\text { 5. Vertical and horizontal screen orien- } \\
\text { tation }\end{array}$ & 4.03 & 0.17 & 4 & 4 & 4 & 0 & 0 \\
\hline 6. Spacing between contents & 4.30 & 0.47 & 4 & 4 & 4 & 0 & 0 \\
\hline 7. Automatic Screen lock & 4.03 & 0.17 & 4 & 4 & 4 & 0 & 0 \\
\hline 8. Easy to use touch screen & 4.03 & 0.17 & 4 & 4 & 4 & 0 & 0 \\
\hline 9. Virtual or Physical keyboard & 4.12 & 0.42 & 4 & 4 & 4 & 0 & 0 \\
\hline 10. Error messages & 4.12 & 0.42 & 4 & 4 & 4 & 0 & 0 \\
\hline 11. Contrast & 4.06 & 0.24 & 4 & 4 & 4 & 0 & 0 \\
\hline $\begin{array}{l}\text { 12. Ease of access to the menu and sub- } \\
\text { menus }\end{array}$ & 4.52 & 0.51 & 4 & 5 & 4 & 0 & 0 \\
\hline 13. Accessible data insertion interfaces & 4.03 & 0.30 & 4 & 4 & 4 & 0 & 0 \\
\hline 14. Easy with drag-and- drop features & 4.06 & 0.24 & 4 & 4 & 4 & 0 & 0 \\
\hline $\begin{array}{l}\text { 15. Easy to identify the symbols and } \\
\text { icons used in the application }\end{array}$ & 4.67 & 0.48 & 4 & 5 & 4 & 0 & 0 \\
\hline $\begin{array}{l}\text { 16. Perception of audio notifications and } \\
\text { reminders }\end{array}$ & 4.06 & 0.24 & 4 & 4 & 4 & 0 & 0 \\
\hline $\begin{array}{l}\text { 17. Easy navigation and information } \\
\text { flow }\end{array}$ & 4.12 & 0.33 & 4 & 4 & 4 & 0 & 0 \\
\hline 18. An option to resize the text & 4.03 & 0.30 & 4 & 4 & 4 & 0 & 0 \\
\hline 19. Sound quality & 4.03 & 0.30 & 4 & 4 & 4 & 0 & 0 \\
\hline
\end{tabular}

\section{Conclusion}

At the moment, the world is facing the growth of an aging society. The eye conditions of the senior population as well as the small-screen smartphones affect the use of mobile applications among today's elderly people who are current users of some applications. Thus, the operations by speech are the easiest approach to give commands for human beings. This research hereby presents the development of the mobile application for elderly household accounting using oral commands and touchscreen systems. The content consistency was evaluated by five experts in the field of information technology and accounting in order to select the features for the developed mobile application. Next, the developed mobile application was distributed to the thirty-three elderly people; the results of the training as well as the pre- and post-learning tests showed that the 
samples scored higher on the post-test than on the pre-test. Furthermore, the effectiveness evaluation results of the mobile application based on the accessibility barriers that elderly people could experience while using the mobile application, showed that, among the nineteen indicators, "Ease to identify the symbols and icons used in the application" are easily identified criteria had the highest mean value at 4.67 together with the standard deviation value at 0.48 , followed by "Easy of access to the menu and submenus" with the mean value of 4.52 and the standard deviation of 0.51 . The next highest rated indicator was "Spacing between contents", receiving the mean value of 4.30 and the standard deviation value of 0.47 . The remaining sixteen indicators shared similar mean values, which were, on average, higher than 4.01. This means their effectiveness was rated as high. Overall, the mean was 4.13 and the standard deviation was 0.34 on average, showing the developed mobile application was effective for the elderly users at a high level and high consensus. All of values the interquartile range no more than 1 [34] and the quartile deviation no more than 0.5 [35] in 19 assessment indicators. The elderly users could learn and employ the application on their mobile devices to manage their household accounts effectively. They stated that the distinctive points of the mobile application were the easily-recognized symbols and icons that were used, the ease of access to the menu and submenus, and spacing between the contents. Not only do the elderly people benefit from the application, but normal users can also use it conveniently. With simple clicks on their smartphones, their income and expenditure can be easily tracked on a daily basis. Having this application therefore helps the users develop their financial discipline and reflect on their financial status in order to manage their personal and family finances; it is a tool to reduce the household debts in Thailand as a whole.

\section{Acknowledgement}

I would like to express our gratitude to the Institute for Research and Development, Suan Sunandha Rajabhat University, who offered us the opportunities to conduct this research.

\section{$7 \quad$ References}

[1] Information Center for Older. (2013). The situation of Thai elderly in 2013 Report.

[2] Shryock, H. S. (2004). The methods and materials of demography. New York: Academic Press.

[3] Office of the National Economic and Social Development Council. (2009). Thai society report first quarter of 2019.

[4] Huang, X., Acero, A. and Hon, H. W. (2001). Spoken Language Processing: a guide to theory algorithm and system development. Prentice Hall.

[5] Kumar, K. and Aggarwal, R. K. (2011). Hindi Speech recognition system using HTK. International Journal of Computing and Business Research, 2(2).

[6] Samudravijaya, K. (2003). Speech and Speaker recognition: Tutorial International Workshop on Tech, Development in Indian Languages, Kolkata, Jan 22-24. 
[7] Jurafsky, D. and Martin, J. H. (2009). Speech and Language Processing - An Introduction to Natural Language Processing. Computational Linguistics, and Speech Recognition, Prentice Hall. https://doi.org/10.1162/089120100750105975

[8] Karpagavalli, S. and Chandra, E. (2016). A Review on Automatic Speech Recognition Architecture and Approaches. International Journal of Signal Processing, Image Processing and Pattern Recognition, 9(4):393-404. https://doi.org/10.14257/ijsip.2016.9.4. $\underline{34}$

[9] Vacher, M., Rossato, S. and Portet, F. (2015). Development of Automatic Speech Recognition Techniques for Elderly Home Support: Applications and Challenges. Conference Paper, February 2015.

[10] Hämäläinena, A., Teixeirac, A., Almeidac, N., Meinedoa, H., Fegyód, T. and Diasa, M.S. (2015). Multilingual speech recognition for the elderly: The AALFred personal life assistan. Procedia Computer Science, 67:283 -292. https://doi.org/10.1016/j.procs.2015. $\underline{09.272}$

[11] Baecher, R., Wu, M. and Masimmi, M. (2017). Using participatory activities with senior to critique. build and evaluate mobile phones, ACM.

[12] Nuanmeesri, S. (2018). The augmented reality for teaching Thai students about the human heart. International Journal of Emerging Technologies in Learning. 13(6):203-213. https:// doi.org/10.3991/ijet.v13i06.8506

[13] Nuanmeesri, S. and Poomhiran, L. (2019). Perspective Electrical Circuit Simulation with Virtual Reality. International Journal of Online Engineering. 15(5):28-37. https://doi.org/ 10.3991/ijoe.v15i05.9653

[14] Nuanmeesri, S. (2019). Extended Study of Undergraduate Students' Usage of Mobile Application for Individual Differentiation Learning Support of Lecture-based General Education Subjects. International Journal of Interactive Mobile Technologies. 13(9):99-112. https://doi.org/10.3991/ijim.v13i09.10558

[15] Phaosawad, M. and Kadthajung P. (2015). A development of dhamma retreat management information system: a case study of payayang temple. VRU Research and Development Journal, 10(3):33-42.

[16] Likert, R. (1932). A Technique for the measurement of attitudes. Archives of Psychology, New York University.

[17] Oliveira, C. D., Fioravanti, M. L., Fortes, R. P. M. and Barbosa, E. F. (2018). Accessibility in mobile applications for elderly users: a systematic mapping. Proceding of Conference: 48th Annual Frontiers in Education Conference,1-9. https://doi.org/10.1109/fie.2018.8659 $\underline{017}$

[18] Fortes, R. P. M., Martins. G. A. and Castro, P. C. (2015). A review of senescent's motivation in the use of tactile devices. Procedia Computer Science, 67. https://doi.org/ 10.1016/j.procs.2015.09.282

[19] Hsieh, H. C. L. (2015). Developing mobile application design of virtual pets for caring for the elderly. International Conference on Human Aspects of IT for the Aged Population, Springer, 269-277.

[20] Al-Razgan, M. S., Al-Khalifa, H. S., Al-Shahrani, M. D. and AlAjmi, H. H. (2012). Touchbased mobile phone interface guidelines and design recommendations for elderly people: A survey of the literature, International Conference on Neural Information Processing, Springer, 568-574. https://doi.org/10.1007/978-3-642-34478-7 69

[21] Hellman, R. ()2007. Universal design and mobile devices, in International Conference on Universal Access in Human-Computer Interaction. Springer, 147-156. https://doi.org/10.1007/978-3-540-73279-2_17 
[22] Balata, J., Mikovec, Z. and Slavicek, T. (2015). Koalaphone: touchscreen mobile phone ui for active seniors. Journal on Multimodal User Interfaces. 9(4):263-273. https://doi.org/10.1007/s12193-015-0188-1

[23] Ferron, M., Mana, N. and Mich, O. (2015). Mobile for older adults: towards designing multimodal interaction. Proceedings of the 14th International Conference on Mobile and Ubiquitous Multimedia, ACM, 373-378. https://doi.org/10.1145/2836041.2841211

[24] Angeletou, A., Garschall, M., Hochleitner, C. and Tscheligi, M. (2013). I need to know, i cannot, i do not understand: older users' requirements for a navigation application. Assistive Technology: From Research to Practice, 33:34-39.

[25] Stone, R. (2008). Mobile touch interfaces for the elderly

[26] Santos, M. M., Antonelli, H. L., Rodrigues, S. S., Silva, C. L., Fortes, R. P. and Castro, P. C. (2016). Personalizing health-related ict interface and application: older adults and elderly caregivers preferences. Proceedings of the 7th International Conference on Software Development and Technologies for Enhancing Accessibility and Fighting Infoexclusion, ACM, 331-338. https://doi.org/10.1145/3019943.3019991

[27] Fondevila, J. F., Gascon, M., Carreras, A., Seebach, S. and Zamora, M. J. P. (2015). How elders evaluate apps: A contribution to the study of smartphones and to the analysis of the usefulness and accessibility of icts for older adults. Mobile Media \& Communication, 3(2): 250-266. https://doi.org/10.1177/2050157914560185

[28] Conde, M. A., Garc, F. J. P, and Matell, V. O. (2014). Mobile apps repository for older people. Proceedings of the Second International Conference on Technological Ecosystems for Enhancing Multiculturality, ACM, 725-731. https://doi.org/10.1145/2669711.2669981

[29] Ziat, M., Yao, H. Y., Schmitt, R. and Hayward, V. (2016). Frontpanel: Tangible user interface for touch-screens dedicated to elderly. Proceedings of the $2016 \mathrm{CHI}$ Conference Extended Abstracts on Human Factors in Computing Systems. ACM. 3808-3811. https:// doi.org/10.1145/2851581.2890266

[30] Gonzalo, R. B., Sanchez, R. R., Normand, L. M., Saavedra, B. F. and Jimenez, J. L. (2015). Accessible mobile biometrics for elderly. Proceedings of the 17th International ACM SIGACCESS Conference on Computers \& Accessibility, ACM, 419-420. https:// doi.org/10.1145/2700648.2811332

[31] Renaud, K. and Biljon, J. V. (2010). Worth-centred mobile phone design for older users. Universal Access in the Information Society, 9(4):387-403. https://doi.org/10.1007/s10 209-009-0177-9

[32] Motti, L. G., Vigouroux, N. and Gorce, P. (2015). Improving accessibility of tactile interaction for older users: lowering accuracy requirements to support drag-and-drop interaction. Procedia Computer Science, 67:366-375. https://doi.org/10.1016/j.procs.2015. $\underline{09.281}$

[33] Arab, F., Malik, Y., and Abdulrazak, B. (2013). Evaluation of phonage: an adapted smartphone interface for elderly people. IFIP Conference on Human-Computer Interaction. Springer, 547-554. https://doi.org/10.1007/978-3-642-40498-6 44

[34] Soon, F. F., Pei, E. C. and Fei, P. P. (2013). Development of ICT Competency Standard Using the Delphi Technique. Procedia - Social and Behavioral Sciences. 103:299-314. https://doi.org/10.1016/j.sbspro.2013.10.338

[35] Saedah, S. and Azdalila, A. (2008). Principal's projections on the Malaysian secondary school future curriculum. International Education Studies, 1(4):61-78. 


\section{Author}

Sumitra Nuanmeesri is lecture at Suan Sunandha Rajabhat University, Bangkok 10130 Thailand. She has a Ph.D. in information technology from King Mongkut's University of Technology, North Bangkok. Her research interests include deep learning, computer vision, image processing, data mining, mobile applications, supply chain systems, augmented reality, virtual reality and internet of thing.

Article submitted 2019-09-10. Resubmitted 2019-10-17. Final acceptance 2019-10-18. Final version published as submitted by the authors. 